\title{
THORACIC EPIDURAL ANAESTHESIA FOR MODIFIED RADICAL MASTECTOMY IN CARCINOMA BREAST CASES- A RETROSPECTIVE DESCRIPTIVE STUDY
}

\author{
P. S. Shanmugam¹, Nimi Gopal2, Sowmya Shanmugam³
}

${ }^{1}$ HOD, Department of Anaesthesiology and Critical Care Medicine, Meenakshi Medical College and Research Institute, Enathur, Kanchipuram.

${ }_{2}^{2}$ Postgraduate Student, Department of Anaesthesiology and Critical Care Medicine, Meenakshi Medical College and Research Institute, Enathur, Kanchipuram.

${ }_{3}^{3}$ Postgraduate Student, Department of Anaesthesiology and Critical Care Medicine, Meenakshi Medical College and Research Institute, Enathur, Kanchipuram.

\begin{tabular}{l} 
ABSTRACT \\
\hline BACKGROUND \\
Routinely breast surgeries including Modified Radical Mastectomy have been performed under general anaesthesia. In spite of the \\
availability of many regional anaesthesia techniques for breast surgeries, achievement of complete anaesthesia for extensive \\
oncologic procedures is difficult with the use of field blocks and local infiltrative techniques. Epidural anaesthesia has been \\
associated with fewer postoperative complications and earlier hospital discharge for such cases including Modified Radical \\
Mastectomy with axillary clearance.
\end{tabular}

\section{MATERIALS AND METHODS}

This is a Retrospective Descriptive Study. Informed consent was obtained. With the patient in the lateral decubitus position, under strict aseptic precautions, 18-G Tuohy's needle was inserted at the level of T4 - T5 and the catheter tip was placed at T1 epidural space. A test dose of $2 \mathrm{~mL} \mathrm{2 \%} \mathrm{Lignocaine} \mathrm{with} \mathrm{adrenaline} \mathrm{1:200000} \mathrm{was} \mathrm{given} \mathrm{and} \mathrm{then} 10-13 \mathrm{~mL}$ of $0.5 \%$ Bupivacaine with 30 mcg Inj. Clonidine was given. Level of sensory blockade, need for sedation, intraoperative haemodynamic parameters and postoperative pain scores were noted.

\section{RESULTS}

50 patients belonging to the age group 55 - 70 years of age who underwent oncological breast surgeries including Modified radical mastectomy with axillary clearance under thoracic epidural anaesthesia were reviewed between the periods of Jan 2016 - Sep 2017. Adequate level of sensory blockade B/L was achieved with a Modified Ramsay sedation score of 2 in most patients. Postoperative pain scores were between 0 - 1 in all the patients.

\section{CONCLUSION}

Thoracic epidural anaesthesia can be safely used in geriatric women undergoing Modified Radical Mastectomy for breast carcinoma.

\section{KEYWORDS}

Thoracic Epidural, Modified Radical Mastectomy, Breast Surgery and Geriatric.

HOW TO CITE THIS ARTICLE: Shanmugam PS, Gopal N, Shanmugam S. Thoracic epidural anaesthesia for modified radical mastectomy in carcinoma breast cases- a retrospective descriptive study. J. Evolution Med. Dent. Sci. 2018;7(02):159-161, DOI: $10.14260 /$ jemds/2018/35

\section{BACKGROUND}

Worldwide prevalence of carcinoma of the breast is increasing at an alarming rate and is a leading cause of cancer related mortality in women. In India, prevalence of carcinoma breast varies from 12 - 31 cases per 100,000 women. ${ }^{1}$ Routinely breast surgeries including Modified Radical Mastectomy have been performed under general anaesthesia. Various regional anaesthetic techniques have been described in the literature including brachial plexus blocks, $, 2,3$ intercostal nerve blocks, ${ }^{4}$ field blocks, ${ }^{3}$ local infiltration ${ }^{5}$ and thoracic epidural anaesthesia. ${ }^{6}$

'Financial or Other Competing Interest': None.

Submission 22-11-2017, Peer Review 19-12-2017,

Acceptance 27-12-2017, Published 08-01-2018.

Corresponding Author:

Dr. Nimi Gopal,

No.93, New Ladies Hostel,

MMCHRI, Enathur

Kanchipuram - 631552.

E-mail:nimi_5@yahoo.co.in

DOI: $10.14260 /$ jemds $/ 2018 / 35$
Achievement of complete anaesthesia for extensive oncologic procedures is difficult with the use of field blocks and local infiltrative techniques. Epidural anaesthesia has been associated with fewer postoperative complications and earlier hospital discharge. ${ }^{7}$ We initiated the use of thoracic epidural anaesthesia technique for patients undergoing breast surgeries from Jan 2012 onwards. The high level of patient and surgeon satisfaction with the thoracic epidural technique prompted a retrospective review of our findings with this technique.

\section{MATERIALS AND METHODS}

This is a Retrospective Descriptive Study. After receiving the approval of the Hospital Institutional Ethical Committee, we reviewed 50 oncologic breast procedures performed under thoracic epidural anaesthesia from Jan 2016 - Sep 2017 in our institution.

On the previous day of the surgery, informed consent was obtained after explaining the procedure of Thoracic epidural clearly to the patient. All the patients belonging to the age group of 55 - 70 yrs. were thoroughly examined, investigated 
during the preoperative assessment and were assessed under ASA PS III-IV. On the day of surgery, the patient was shifted to the operation theatre. Basic monitors were connected and baseline parameters (Heart rate, Blood pressure and Oxygen saturation) were recorded. Intravenous access was established with an 18-G IV cannula. The patients were positioned in the right lateral decubitus position. Under strict aseptic precautions, T4 - T5 intervertebral space was identified, skin was infiltrated with local anaesthetic, 18-G Tuohy's needle was inserted into the epidural space using loss of resistance technique. Catheter was inserted and the tip of the catheter was placed at T1. Test dose of $2 \mathrm{~mL}$ of $2 \%$ Lignocaine with adrenaline was given. $10-13 \mathrm{~mL}$ of $0.5 \%$ Bupivacaine with $30 \mathrm{mcg}$ of Inj. Clonidine was given through the epidural catheter. The epidural catheter was fixed securely with plasters and the patient placed supine.

Oxygen at $6 \mathrm{~L} / \mathrm{min}$ was administered via facemask during the surgery; 5 mins after giving the drug, the level of sensory blockade was noted using the pinprick method. Adequate level of sensory blockade from T1 - T10 was achieved bilaterally. Intraoperative haemodynamic parameters were recorded. Need for sedation was assessed using Modified Ramsay's sedation scale. Patients were asked to grip the investigator's hand tightly to confirm the sparing of Brachial plexus blockade except T1 fibres. Epidural top-up was given through the epidural catheter based on the duration of the surgery. After the surgery was over, patients were shifted to the recovery room. Heart rate, BP, assessment of pain using Visual Analog Scale (VAS) was done. Patients were started on continuous epidural infusion of $0.125 \%$ Bupivacaine.

Repeated ANOVA test was done for the postoperative pain relief scoring using SPSS 25.0.

\section{RESULTS}

50 patients belonging to the age group 55 - 70 years of age who underwent oncological breast surgeries including Modified Radical Mastectomy under Thoracic epidural anaesthesia were reviewed between the periods of Jan. $2106-$ Sep. 2017.

\begin{tabular}{|c|c|}
\hline Age Group (Years) & No. of Patients \\
\hline $55-60$ & 13 \\
\hline $61-65$ & 34 \\
\hline $66-70$ & 3 \\
\hline Total & $\mathbf{5 0}$ \\
\hline Table 1. Age Wise Distribution of Patients \\
\hline
\end{tabular}

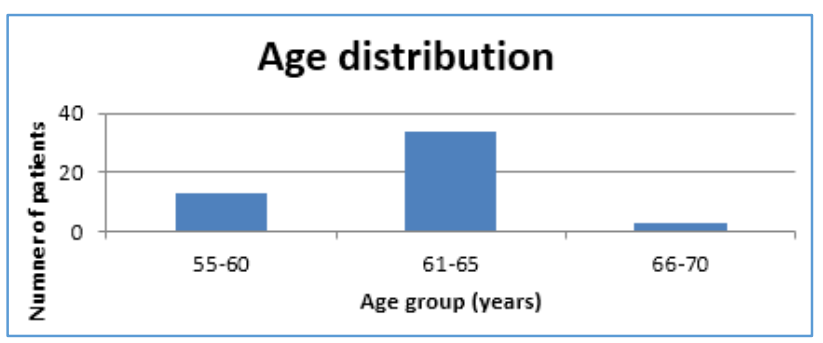

Graph 1. Age Distribution

\begin{tabular}{|c|c|}
\hline Co-Existing Condition & Number of Patients \\
\hline IHD & 3 \\
\hline Hypertension & 10 \\
\hline IHD with Hypertension & 2 \\
\hline Diabetes Mellitus & 8 \\
\hline Bronchial Asthma & 1 \\
\hline \multicolumn{2}{|c|}{ Table 2. Co-Existing Conditions } \\
\hline
\end{tabular}

\begin{tabular}{|c|c|c|c|c|}
\hline Score & 1 & 2 & 3 & $4-6$ \\
\hline $\begin{array}{c}\text { Number of } \\
\text { Patients }\end{array}$ & 2 & 40 & 8 & 0 \\
\hline \multicolumn{3}{|c|}{$\begin{array}{c}\text { Table 3. Intraoperative Sedation Score } \\
\text { (Modified Ramsay Sedation Score) }\end{array}$} \\
\hline
\end{tabular}

Patients were sedated with Inj. Midazolam $(0.05 \mathrm{mg} / \mathrm{kg})$ before the start of the surgery and repeated intraoperative if the score was 1.

\begin{tabular}{|c|c|}
\hline $\begin{array}{c}\text { Sedation } \\
\text { Scale }\end{array}$ & Clinical Response \\
\hline 0 & Paralysed, Unable to evaluate \\
\hline 1 & Awake \\
\hline 2 & Lightly sedated \\
\hline 3 & Moderately sedated, follows simple commands \\
\hline 4 & Deeply sedated, responds to non-painful stimuli \\
\hline 5 & Deeply sedated, responds only to painful stimuli \\
\hline 6 & Deeply sedated, unresponsive to painful stimuli \\
\hline \multicolumn{2}{|c|}{ Table 4. Modified Ramsay Sedation Scale } \\
\hline
\end{tabular}

\begin{tabular}{|c|c|}
\hline Complication & Number of Patients \\
\hline Bradycardia & 2 \\
\hline Hypotension & 13 \\
\hline Nausea & 1 \\
\hline Respiratory Depression & - \\
\hline \multicolumn{2}{|c|}{ Table 5. Incidence of Complications } \\
\hline
\end{tabular}

Two patients had bradycardia (HR $<60$ per minute), which was attributed to Inj. Clonidine. Hypotension was seen in 13 patients, but did not require the use of vasopressors. Only 1 patient had nausea towards the end of the procedure.

\begin{tabular}{|c|c|c|c|}
\hline Time Interval & VAS 0 & VAS 1 - 5 & VAS 6 - 10 \\
\hline 4 hours & 50 & 0 & 0 \\
\hline 8 hours & 49 & 1 & 0 \\
\hline 12 hours & 50 & 0 & 0 \\
\hline
\end{tabular}

\section{Table 6. Postoperative Pain Score at 4, 8 and 12 hrs.}

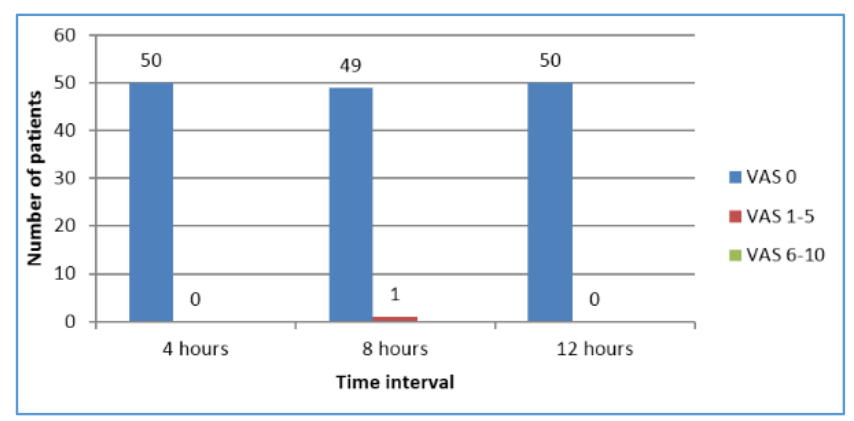

Graph 2. Post-Operative Pain Scoring

Postoperatively, patients received a continuous epidural infusion of $0.125 \%$ Bupivacaine at $3-4 \mathrm{~mL} /$ hour. Almost, all patients had adequate pain relief. $F$ value was 1.000 . Although, there was not any significant difference between the different time intervals, there was no need for rescue analgesia for 12 hours postoperatively. 


\section{DISCUSSION}

With the increase in the incidence of radical surgeries for breast carcinomas, there is a need for the advent of an anaesthetic technique that provides adequate intraoperative anaesthesia and postoperative analgesia without collateral effects.

As per the results of our study, thoracic epidural anaesthesia provides adequate sensory blockade throughout the surgery without much change in the intraoperative haemodynamic parameters. This will be of great advantage in the perioperative management of geriatric patients undergoing oncological breast surgeries with poor cardiopulmonary reserve. ${ }^{8}$

Balzarena et al demonstrated the safety and superiority of thoracic epidural over general anaesthesia in 40 patients scheduled for mastectomy. In that study, thoracic epidural was found to be superior in terms of haemodynamic stability, lower need for analgesia, reduced postoperative nausea and vomiting and shorter duration of hospitalisation. ${ }^{8}$ Similar observations have been reported by other researchers. ${ }^{9,10,11}$

Providing adequate postoperative analgesia is of prime importance in the geriatric age group. Thoracic epidural provides excellent pain relief and reduces the pulmonary complications in the geriatric population as they are more prone to hypoxemia and have a shallow breathing pattern due to pain, thereby augmenting hypoxemia. 12

General anaesthetic agents, mainly opioids have been proven to suppress the immune system and promote cancer metastasis in virtue of their mechanism of action. ${ }^{13}$ Almost all anaesthetic agents have been shown to have a negative impact on various components of the immune system. Volatile anaesthetics appear to have a pronounced negative effect on immune function and cancer spread. They have also been shown to upregulate hypoxia-inducible factors. In contrast to volatile agents, Propofol seems to exhibit a beneficial effect in terms of reducing inflammatory cytokines and thereby inhibiting cancer spread. Local anaesthetics themselves seem to be protective against tumour growth and metastasis via several mechanisms including direct cytotoxicity and induction of apoptosis; inhibition of proliferation, migration and invasion. Hence, regional anaesthesia avoids exposure to factors that result in cancer progression such as stress hormone release, uncontrolled or poorly controlled pain, exposure to volatile anaesthetics and opioids. ${ }^{14}$

The infrequent use of thoracic epidural anaesthesia for oncologic beast surgeries may be attributed to the fear of potential complications of thoracic epidural such as misplacement of the catheter, spinal tap, epidural abscess or spinal haematoma. We did not have any such procedure related complications, as such complications are extremely rare with the increased expertise and precautions taken by the anaesthesiologist.

The potential advantage of thoracic epidural technique in terms of earlier hospital discharge was not followed up adequately in our study. The retrospective nature of the study also creates an opportunity for bias.

\section{CONCLUSION}

Thoracic epidural anaesthesia can be safely used in geriatric women undergoing Modified Radical Mastectomy for breast carcinoma with significant postoperative analgesia, reduced perioperative complications, preventing metastasis and hypoxemia.

\section{REFERENCES}

[1] Agarwal G, Ramakant P. Breast Cancer Care in India: The current scenario and the challenges for the future. Breast Care (Basel) 2008;3(1):21-7.

[2] Fassoulaki A. Brachial plexus block for pain relief after modified radical mastectomy. Anesth Analog 1982;61(12):986-7.

[3] Labat G. Regional anesthesia: its technique and clinical application. $2^{\text {nd }}$ edn. Philadelphia: WB Saunders 1928:381-9.

[4] Atansoff PG, Alon E, Weiss BM. Intercostal nerve block for lumpectomy: superior postoperative pain relief with bupivacaine. J Clin Anesth 1994;6(1):47-51.

[5] Dennison AR, Watkins RM, Ward ME, et al. Simple Mastectomy trader local anaesthesia. Plast Reconstr Surg 1979;63:299-303.

[6] Nesmith RL, Herring SH, Marks MW, et al. Early experience with high thoracic epidural anesthesia in outpatient submuscular breast augmentation. Ann Plastic Surg 1990;24(4):299-302.

[7] Parnass SM, McCarthy RJ, Bach BR, et al. Beneficial impact of epidural anesthesia on recovery after outpatient arthroscopy. Arthroscopy 1993;9(1):91-5.

[8] Balzarena SD. Comparative study between thoracic epidural block and general anaesthesia for oncologic mastectomy. Rev Bras Anaestesiol 2008;58(6):561-8.

[9] Lynch EP, Welch KJ, Carabuena JM, et al. Thoracic epidural anaesthesia improves outcome after breast surgery. Ann Surg 1995;222(5):663-9.

[10] Asegaonkar BN, Zine SR, Takalkar UV, et al. Thoracic epidural anaesthesia for modified radical mastectomy in carcinoma of breast patient with Chronic Obstructive Pulmonary Disease - a case report. IJCRI 2013;4(10):546-50.

[11] Shah S, Shah B, Deb C. Study of breast surgery under thoracic epidural analgesia. Sch J App Med Sci 2016;4(6F):2244-7.

[12] Groeben H. Effect of high thoracic epidural anesthesia and local anesthetic on bronchial hyperreactivity. J Clin Monit Comput 2000;16(5-6):457-63.

[13] Tavare AN, Perry NJS, Benzonana LL, et al. Cancer recurrence after surgery: direct and indirect effects of anesthetic agents. Int J Cancer 2012;130(6):1237-50.

[14] Tedore T. Regional anaesthesia and analgesia: relationship to cancer recurrence and survival. BJA 2015;115(Suppl 2):ii34-ii45. 